\title{
Clinical Characteristics Associated With Lenvatinib-induced Fistula and Tumor-related Bleeding in Patients With Thyroid Cancer
}

\author{
YUKIKO STAUB ${ }^{1}$, AKIHIRO NISHIYAMA $^{2}$, YUKIO SUGA ${ }^{1}$, \\ MIKIYA FUJITA $^{1}$, RYO MATSUSHITA $^{1}$ and SEIJI YANO ${ }^{2}$ \\ ${ }^{1}$ Department of Clinical Pharmacy and Healthcare Sciences, Faculty of Pharmacy, Institute of Medical, \\ Pharmaceutical and Health Sciences, Kanazawa University, Kanazawa, Japan; \\ ${ }^{2}$ Division of Medical Oncology, Cancer Research Institute, Kanazawa University, Kanazawa, Japan
}

\begin{abstract}
Background: Lenvatinib has become an important treatment option for advanced thyroid cancer. Fistula and tumorrelated bleeding are life-threatening adverse effects that are triggered by tumor shrinkage. The aim of this study was to evaluate basic parameters, such as time and tumor shrinkage level, and analyze patient characteristics that might be related to onset of complications. Patients and Methods: A retrospective study of 16 patients who received lenvatinib for thyroid cancer treatment was performed. Results: Fistula was observed in two patients $(12.5 \%)$, while tumor-related bleeding was observed in one (6.3\%). Complications were found to appear at 10.4 weeks from initiation and with tumor decrease of $19.2 \%$. Risk factors for complications were identified as anaplastic histological type, tumor invasion, and leukocytopenia induced by lenvatinib. Conclusion: Individual dose adjustment is needed with respect to these features in order to manage severe adverse effects induced by lenvatinib.
\end{abstract}

Salvage therapy for advanced thyroid cancer has been limited until recently. Since several clinical trials proved the efficacy of multi-targeted tyrosine kinase inhibitors (TKIs) against thyroid cancer, they have become important options in clinical practice (1-4). Lenvatinib is a TKI that inhibits tumor growth and angiogenesis activity by inhibiting vascular endothelial growth factor receptor (VEGFR) 1-3, fibroblast growth factor receptor (FGFR) 1-4, platelet-derived growth factor receptor $\alpha$

Correspondence to: Yukio Suga, Department of Clinical Pharmacy and Healthcare Sciences, Faculty of Pharmacy, Institute of Medical, Pharmaceutical and Health Sciences, Kanazawa University, Takaramachi 13-1, Kanazawa, Ishikawa 920-8641 Japan. Tel: +81 762672831, Fax: +81 762672831, e-mail: suga@staff.kanazawa-u.ac.jp

Key Words: Fistula, bleeding, lenvatinib, thyroid cancer, angiogenesis inhibitor.
(PDGF-R), RET and KIT signaling pathways $(2,5)$. In the phase III, randomized, placebo-controlled trial (SELECT), conducted on 261 patients with radioiodine-refractory differentiated thyroid cancer (DTC), lenvatinib significantly prolonged median progression-free survival by 14.7 months compared to the placebo group, with a response rate of $64.8 \%$ (1). Lenvatinib also showed good therapeutic effects in the phase II trial including anaplastic (ATC) and medullary thyroid cancer (MTC), which have a relatively low prevalence (6-8).

Despite benefit from lenvatinib, previous studies have also shown that it causes various adverse effects with a high frequency, which indicates the need for careful management (9). In the SELECT trial, the incidence of adverse effects of any grade and those of grade 3 or more were as high as $97.3 \%$ and $75.9 \%$, respectively (1). They resulted in dose interruption in $82.4 \%$ of patients and dose reduction in $67.8 \%$ of patients. Fistula and tumor-related bleeding are life-threatening complications which occur subsequent to tumor shrinkage. Since cases of death from these complications have actually been reported, they are problems of growing concern, although they occur with a low frequency $(1,8,10,11)$. However, there are only a few case reports of such complications, and neither fistula nor tumor-related bleeding induced by TKIs has been studied systematically (12-14). In this study, we focused on fistula and tumor-related bleeding induced by lenvatinib in patients with thyroid cancer. The aim was to evaluate basic parameters such as time and tumor shrinkage level, and to analyze patient characteristics which might be related to onset of complications.

\section{Patients and Methods}

Study design and population. A retrospective study was performed. All patients received lenvatinib for thyroid cancer at Kanazawa University from May 2015 to March 2018. The patients' background characteristics are presented in Table I. This study was performed 
with the approval of the clinical research ethics committee of Kanazawa University Hospital [approval number 2017-312 (2746)].

Evaluation of fistula and tumor-related bleeding and related factors. In this study, fistula and tumor-related bleeding were regarded as common complications triggered by tumor shrinkage. The onset of these complications was evaluated by interpretation of computed tomographic (CT) images and clinical symptoms documented in the medical records. Adverse events were evaluated according to National Cancer Institute Common Terminology Criteria for Adverse Events (CTCAE) version 5.0 (15). Assessments of tumors were conducted using CT imaging according to Response Evaluation Criteria in Solid Tumors (RECIST) version 1.1 (16). Tumor size was determined as the sum of measurable target lesions. Focusing on specific cases of fistula or tumor-related bleeding, the tumor-shrinkage rate (\%/week) of all target lesions was calculated from baseline to the point of the event onset. The cutoff value obtained from the calculation of the average tumor-shrinkage rate minus twice the standard deviation (SD) was determined as the high-risk shrinkage rate in this study and used for dose-dependence analysis. Text data are reported as the mean \pm SD .

Statistical analysis. Statistical and graphical analyses were performed using R software version 3.5.1 ( $\mathrm{R}$ Foundation for Statistical Computing, Vienna, Austria). Patient characteristics related to the development of fistula or tumor-related bleeding were explored by univariate logistic regression analysis, and the chi-squared test based on likelihood ratio for evaluating model fit. Dose-dependence of the tumor-shrinkage rate was analyzed by univariate logistic regression analysis. Two logistic models were considered regarding the different degree of drug response: A tumor-shrinkage model and a diseasecontrol model. The response parameter was change in tumor size corrected by time (\%/week) of all target lesions from the previous measurement. The dependent variable was whether the individual tumor-shrinkage rate (\%/week) at each measuring point achieved target values. The target value was the high-risk shrinkage rate for the tumor-shrinkage model, while it was $0 \%$ /week and no appearance of new malignant lesions for the disease-control model. Similarly, the explanatory variable was the average daily dose of lenvatinib from the previous CT examination to the assessment point, including druginterrupted periods. In these models, logit and probability (Prob) were described using the following formula including a linear-proportional term with dosage as the drug-exposure parameter:

$$
\begin{aligned}
& \text { Logit }=\text { Ln } \frac{\text { Prob }}{1-\text { Prob }}=\text { intercept }+ \text { slope } x \text { dose } \\
& \operatorname{Prob}=\frac{1}{1+\operatorname{Exp}(- \text { Logit })}
\end{aligned}
$$

Cutoff values were calculated as the dosage that provided $50 \%$ event probability from the above formula in each model.

\section{Results}

Patient characteristics. Sixteen patients were included in this study, and their characteristics are shown in Table I. All patients, except for three ATC cases, had postoperative

\begin{tabular}{|c|c|}
\hline Characteristic & Value \\
\hline \multicolumn{2}{|l|}{ Age, years } \\
\hline Median (range) & $66(49-83)$ \\
\hline \multicolumn{2}{|l|}{ Body weight, $\mathrm{kg}$} \\
\hline Median (range) & $58.3(42.4-85.6)$ \\
\hline \multicolumn{2}{|l|}{ Body surface area, $\mathrm{m}^{2}$} \\
\hline Median (range) & $1.58(1.32-2.06)$ \\
\hline \multicolumn{2}{|l|}{ Gender, $\mathrm{n}$} \\
\hline Male/female & $8 / 8$ \\
\hline \multicolumn{2}{|l|}{ ECOG performance status, $n$} \\
\hline 0 & 3 \\
\hline 1 & 10 \\
\hline 2 & 1 \\
\hline 3 & 2 \\
\hline \multicolumn{2}{|l|}{ Prior treatment, $\mathrm{n}$} \\
\hline Surgery & 13 \\
\hline Radioiodine/external radiation & $9 / 6$ \\
\hline Sorafenib/cytotoxic agents & $2 / 3$ \\
\hline \multicolumn{2}{|l|}{ Histological type, $\mathrm{n}$} \\
\hline Papillary & 9 \\
\hline Follicular & 3 \\
\hline Anaplastic & 3 \\
\hline Poorly differentiated & 1 \\
\hline \multicolumn{2}{|l|}{ Target lesions, $\mathrm{n}$} \\
\hline Any & 15 \\
\hline Lymph node & 11 \\
\hline Lung & 6 \\
\hline Thyroid & 2 \\
\hline Esophagus & 2 \\
\hline Brain & 2 \\
\hline \multicolumn{2}{|l|}{ Tumor invasion, $\mathrm{n}$} \\
\hline Any & 7 \\
\hline Vessel & 6 \\
\hline Esophagus & 2 \\
\hline Skin & 2 \\
\hline Trachea & 0 \\
\hline \multicolumn{2}{|c|}{ Median baseline tumor size (range), $\mathrm{mm}$} \\
\hline All target lesions $(\mathrm{n}=15)$ & $61.0(24.0-135.0)$ \\
\hline Invasive lesions $(n=7)$ & $48.8(16.5-117.0)$ \\
\hline
\end{tabular}

Table I. Basic patient characteristics.

ECOG: Eastern Cooperative Oncology Group.

recurrence. Papillary cancer was the most common histological subtype $(56.3 \%)$, followed by follicular $(18.8 \%)$, anaplastic (18.8\%), and poorly differentiated (6.3\%) cancer. Seven patients $(43.8 \%)$, including all cases of ATC, had tumor invasion to surrounding tissues or organs such as vessels, esophagus, skin, or trachea.

Typical case presentation. Figure 1 shows CT images of a typical case of fistula in a 60-year-old man with ATC. A tumor of $26.4 \mathrm{~mm}$ in diameter was located at the right thyroid with invasion into the esophagus (Figure 1A). The tumor was also compressing the trachea. Subsequent to the patient starting lenvatinib therapy, the tumor size obviously 
A

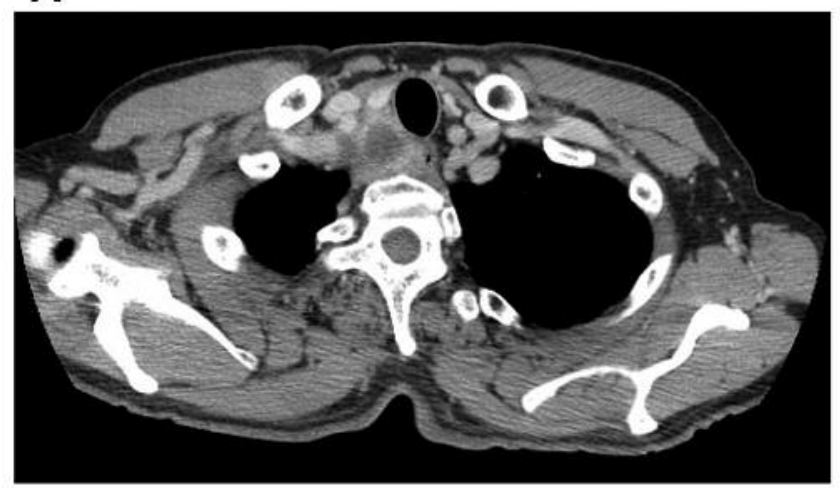

B

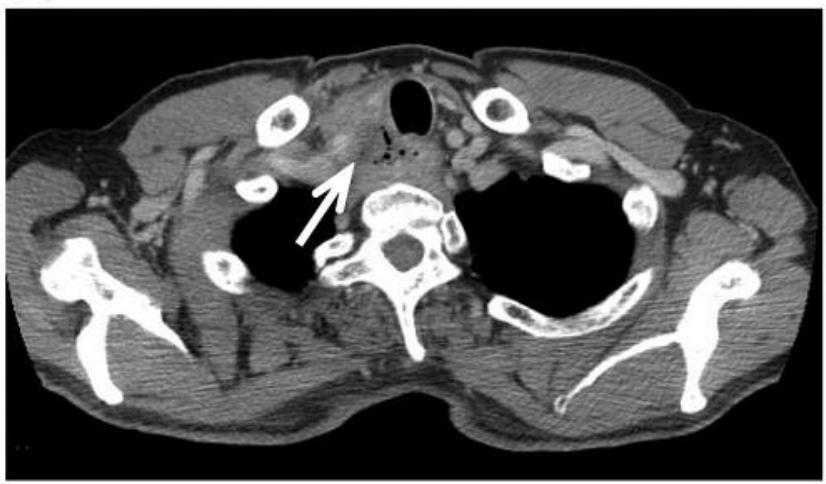

Figure 1. Computed tomographic images of a typical case of fistula, in a 60-year-old man with anaplastic thyroid cancer. A tumor was located on the right thyroid with invasion to the esophagus at baseline (A). After 9.6 weeks' of lenvatinib therapy (B), tracheoesophageal fistula formation was confirmed where the tumor had been originally located.

decreased well. Eight weeks after initiation of lenvatinib, tracheoesophageal fistula formation was suspected where the tumor had been originally located from CT images. At that time, the patient had noticed no symptoms, but subsequently he began to feel anterior chest pain and fever at 9.6 weeks, with the fistula exacerbated on CT images (Figure 1B). Lenvatinib was immediately interrupted, and antimicrobial therapy was given for mediastinitis under food-deprived condition. After 4.0 weeks of lenvatinib interruption, the patient seemed to recover from the tracheoesophageal fistula based on the CT images, esophagram images, and the lack of subjective symptoms. Lenvatinib was carefully restarted under percutaneous endoscopic gastrostomy tube placement because of tumor growth and swallowing difficulty. However, the patient experienced recurrent fistula formation and blood spitting until medication ended.

Incidence of fistula and of tumor-related bleeding. Fistula or tumor-related bleeding occurred in $18.8 \%(3 / 16)$ of patients, consisting of $12.5 \%(2 / 16)$ of a tracheoesophageal fistula and $6.3 \%(1 / 16)$ of tumor-related bleeding. Although the development of a fistula or tumor-related bleeding resulted in drug interruption in all cases, there were no deaths as a result of these complications in this study.

Risk factors related to development of a fistula or tumorrelated bleeding. It was considerable that the onset of complications might be predicted by factors in addition to tumor shrinkage. Therefore, we conducted risk-factor analysis to clarify what kind of factors of patients would be related to development of complications (Table II). The following patient characteristics were significant: ATC histological type; tumor invasion to vessels, esophagus, skin, or trachea; and grade 2 or more leukocytopenia caused by lenvatinib.
Change in dose intensity and tumor size over the treatment period. Figure 2A shows changes in dose intensity over the treatment period for each patient combined with the time to each adverse event. Lenvatinib was started at a high dosage at the maximum of $24 \mathrm{mg}$ per patient. However, dose intensity decreased and was sometimes interrupted with ongoing treatment, indicating that the dose was adjusted for individual tolerability. A total of 82 points of tumor-size data including baseline data were available from 15 patients who had at least one measurable target lesion. Change in tumor size of all target lesions (Figure 2B) and invasive lesions (Figure 2C) are described from baseline over the duration of treatment. The best overall response was partial response in $50.0 \%(8 / 16)$, stable disease in $43.8 \%$ (7/16), and not evaluable in $6.3 \%(1 / 16)$. The average time to developing a fistula or tumor-related bleeding was $10.4 \pm 2.5$ weeks from initiation of lenvatinib. The average degree of tumor shrinkage at the time of occurrence of complications was $19.2 \pm 4.4 \%$ for all target lesions, and $19.3 \pm 3.6 \%$ for invasive lesions. The average tumor-shrinkage rate was $1.97 \pm 0.82 \% /$ week for all target lesions, and $1.99 \pm 0.84 \% /$ week for invasive lesions. Since time-related change in tumor size had a practically similar tendency comparing between all target lesions and invasive lesions, we used data from all target lesions for further analyses. It was also conceivable that tumor size decreased rapidly in the relatively early phase, followed by a gradual decline in the relatively late phase from the graphical features, which was in parallel with dose changes. Combined with these perceptions described above, we presume that the tumor-shrinkage rate was dosedependent. The high-risk shrinkage rate was found to be $0.33 \% /$ week based on average tumor-shrinkage rate minus twice the standard deviation in the cases who developed fistula or tumor-related bleeding. 
Table II. Risk factors for fistula or tumor-related bleeding on logistic regression analysis.

\begin{tabular}{|c|c|c|c|c|c|}
\hline \multirow[t]{2}{*}{ Characteristic } & \multicolumn{2}{|c|}{ Complication } & \multicolumn{2}{|c|}{ Odds ratio } & \multirow[b]{2}{*}{$p$-Value ${ }^{\#}$} \\
\hline & Yes & No & Estimate & $95 \% \mathrm{CI}$ & \\
\hline \multicolumn{6}{|l|}{ Histological type } \\
\hline ATC & 2 & 1 & 3.19 & \multirow[t]{2}{*}{$1.61-1.98$} & \multirow[t]{2}{*}{$\mathbf{0 . 0 3 3}$} \\
\hline Other & 1 & 12 & Ref & & \\
\hline \multicolumn{6}{|l|}{ History of cytotoxic chemotherapy } \\
\hline Yes & 1 & 2 & 2.75 & \multirow[t]{2}{*}{$0.16-46.80$} & \multirow[t]{2}{*}{0.497} \\
\hline No & 2 & 11 & Ref & & \\
\hline \multicolumn{6}{|l|}{ History of external radiation } \\
\hline Yes & 0 & 6 & $\mathrm{NC}$ & \multirow[t]{2}{*}{$\mathrm{NC}$} & \multirow[t]{2}{*}{0.073} \\
\hline No & 3 & 7 & - & & \\
\hline \multicolumn{6}{|l|}{ History of radioiodine } \\
\hline Yes & 1 & 8 & 0.31 & \multirow[t]{2}{*}{$0.02-4.41$} & \multirow[t]{2}{*}{0.375} \\
\hline No & 2 & 5 & Ref & & \\
\hline \multicolumn{6}{|l|}{ History of sorafenib } \\
\hline Yes & 0 & 2 & $\mathrm{NC}$ & \multirow[t]{2}{*}{$\mathrm{NC}$} & \multirow[t]{2}{*}{0.344} \\
\hline No & 3 & 11 & - & & \\
\hline \multicolumn{6}{|l|}{ Tumor invasion } \\
\hline Yes & 3 & 4 & $\mathrm{NC}$ & \multirow[t]{2}{*}{$\mathrm{NC}$} & \multirow[t]{2}{*}{0.015} \\
\hline No & 0 & 9 & - & & \\
\hline \multicolumn{6}{|l|}{ ECOG performance status } \\
\hline$\geq 2$ & 0 & 3 & $\mathrm{NC}$ & \multirow[t]{2}{*}{$\mathrm{NC}$} & \multirow[t]{2}{*}{0.237} \\
\hline 0 or 1 & 3 & 10 & - & & \\
\hline \multicolumn{6}{|l|}{ Grade of leukocytopenia } \\
\hline$\geq 2$ & 3 & 4 & $\mathrm{NC}$ & \multirow[t]{2}{*}{$\mathrm{NC}$} & 0.015 \\
\hline 0 or 1 & 0 & 9 & - & & \\
\hline Grade of thrombocytopenia & & & & & \\
\hline$\geq 2$ & 1 & 3 & 1.67 & $0.11-25.40$ & 0.718 \\
\hline 0 or 1 & 2 & 10 & $\operatorname{Ref}$ & & \\
\hline Grade of anemia & & & & & \\
\hline$\geq 2$ & 2 & 5 & 3.20 & $0.23-45.20$ & 0.375 \\
\hline 0 or 1 & 1 & 8 & Ref & & \\
\hline Gender & & & & & \\
\hline Male & 1 & 7 & 0.43 & $0.03-5.99$ & 0.519 \\
\hline Female & 2 & 6 & Ref & & \\
\hline Age, per year increase & & & 1.01 & $0.88-1.15$ & 0.897 \\
\hline Daily dosage at 10 weeks, per mg increase & & & 0.62 & $0.32-1.17$ & 0.070 \\
\hline Baseline tumor size, per mm increase $(n=15)$ & & & 1.02 & $0.98-1.06$ & 0.365 \\
\hline Body weight, per $\mathrm{kg}$ increase & & & 1.00 & $0.90-1.11$ & 0.998 \\
\hline
\end{tabular}

CI: Confidence interval; NC: not calculable. ${ }^{\#}$ Chi-squared test. Significant $p$-values are shown in bold.

Dose-dependence of the tumor-shrinkage rate. Logistic model analyses for dose-dependence of the tumor-shrinkage rate is shown in Figure 3 and Table III. The recorded data for the tumor size change comprised 27 points $(32.9 \%)$ and 44 points $(53.7 \%)$ that reached the target values for tumor shrinkage model and disease control model, respectively. Only dose was selected as an explanatory variable, while risk factors detected from the above analysis were not significantly related in these models. The probability of change of tumor size over the highrisk shrinkage rate (Figure 3A) and of disease control (Figure $3 \mathrm{~B})$ was found to increase significantly with dose. The dosage that provided a $50 \%$ probability of high-risk tumor shrinkage calculated from the logistic curve was $11.62 \mathrm{mg}$. In the same way, the dosage that provided a $50 \%$ probability of disease control, which represented tumor size being maintained without growing, was $5.48 \mathrm{mg}$.

\section{Discussion}

As far as we are aware, this is the first report to clarify basic parameters and patient factors of lenvatinib-induced fistula formation and tumor-related bleeding using statistical techniques. As anticancer treatments continue to advance scientifically, complications caused by effective treatment, 


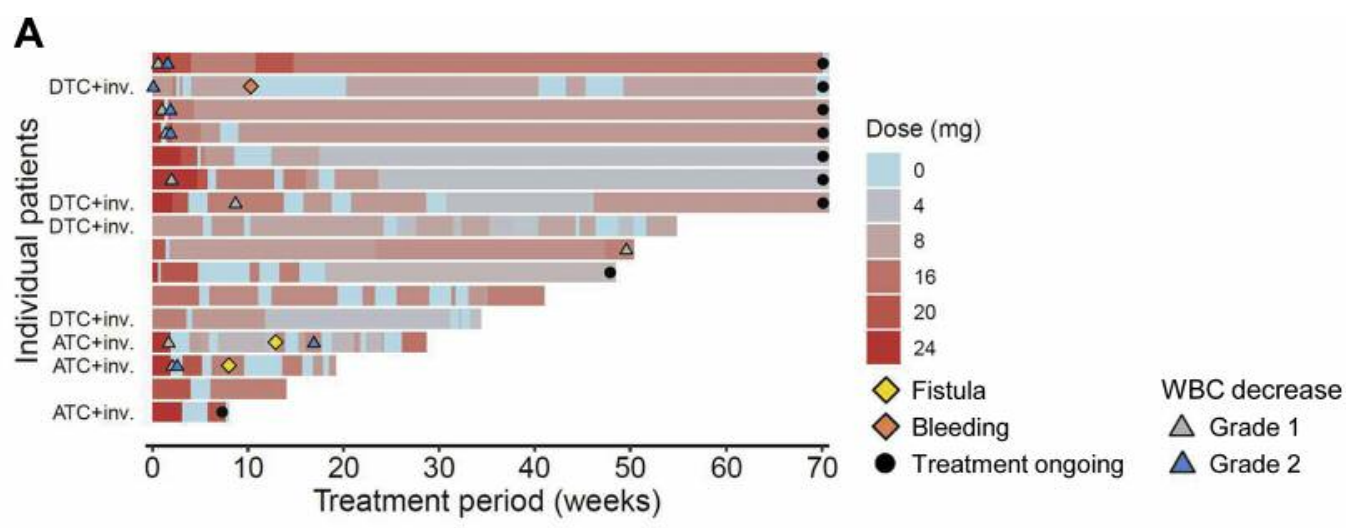

B

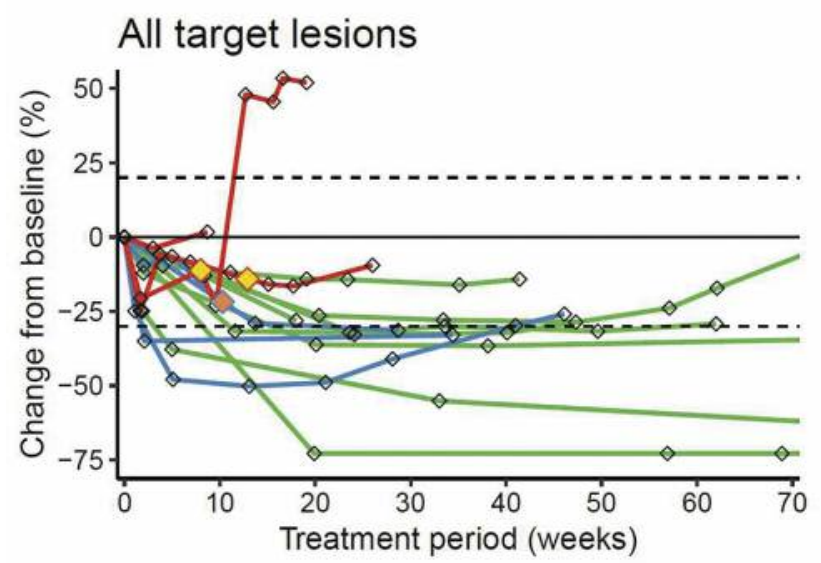

C

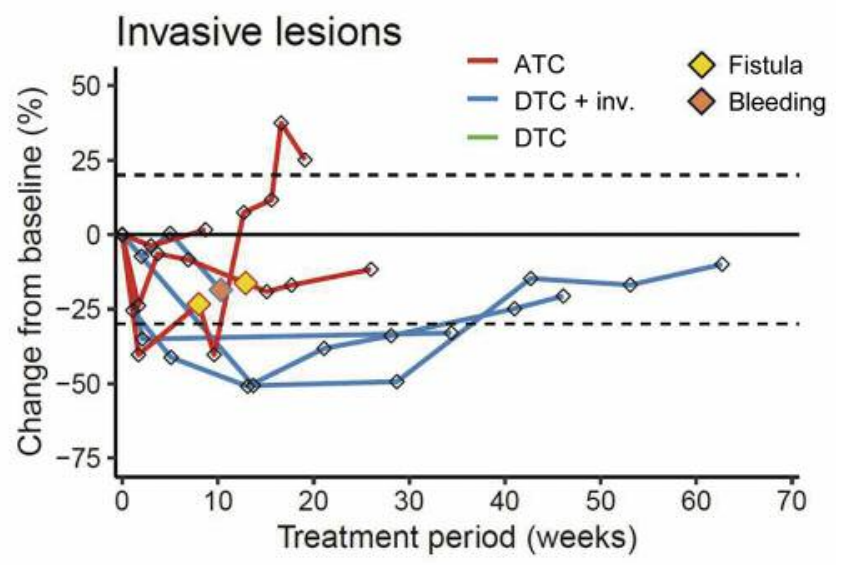

Figure 2. Change in dose intensity and tumor size over the period of treatment with lenvatinib in patients with thyroid cancer. Changes in dose intensity over the treatment period are shown combined with the time to each event. Lenvatinib was started at a high dosage, with a maximum of $24 \mathrm{mg}$, whereas the dose intensity was reduced and sometimes interrupted with ongoing treatment (A). Change in tumor size from baseline of all target lesions (B) and invasive lesions (C) are depicted. ATC: Anaplastic thyroid cancer; DTC: differentiated thyroid cancer; inv.: invasion by tumor; WBC: white blood cell.

such as fistula and tumor-related bleeding, will require more careful attention. The average degree of tumor shrinkage leading to a fistula or tumor-related bleeding was found to be $19.2 \%$ from baseline. It was notable that complications could occur even if the tumor size decreased to less than the level of partial response according to RECIST. Moreover, a $19.2 \%$ tumor decrease would be expected to be reached with high frequency, considering the high response rate observed in the phase II trials (6-8). Similarly, the average time to developing a fistula or tumor-related bleeding was 10.4 weeks from the start of lenvatinib. This might be considered as early in the long-term course of therapy for thyroid cancer. Moreover, there are case reports that a fistula or hemorrhage appeared at 9 and 16 days from initiation of lenvatinib in patients with differentiated thyroid cancer, which was approximately 5 to 10 times earlier than the present result $(1,13)$. In contrast, there is also a case report
Table III. Estimated parameters using logistic models.

\begin{tabular}{lrrrrrrrr}
\hline & \multicolumn{3}{c}{ Tumor shrinkage model } & & \multicolumn{3}{c}{ Disease control model } \\
\cline { 2 - 3 } & Estimate & SD & $p$-Value & & Estimate & SD & $p$-Value \\
\hline Intercept & -2.763 & 0.739 & & & -0.970 & 0.618 & \\
Slope & 0.238 & 0.070 & $<0.001$ & & 0.177 & 0.068 & 0.002 \\
\hline
\end{tabular}

SD: Standard deviation.

that a fistula appeared 6 months after starting lenvatinib in a patient with MTC (12). Although the degree of tumor shrinkage was not noted in those cases, these complications might be explained by rapid tumor decrease within a short time. The tumor-shrinkage rate might very well be related to the development of complications. 
A

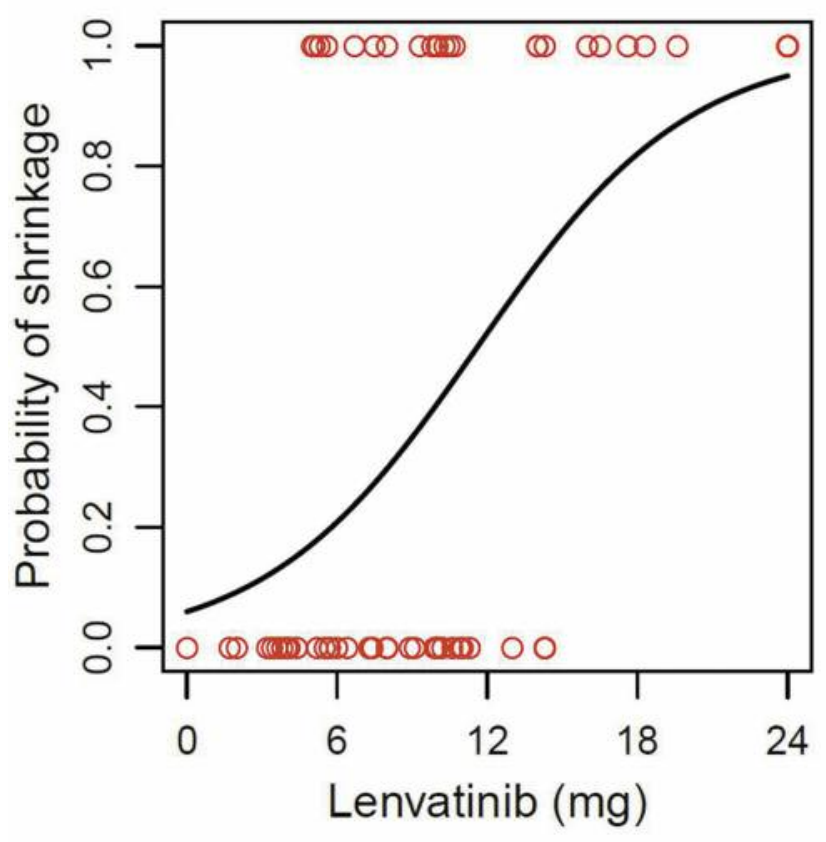

B

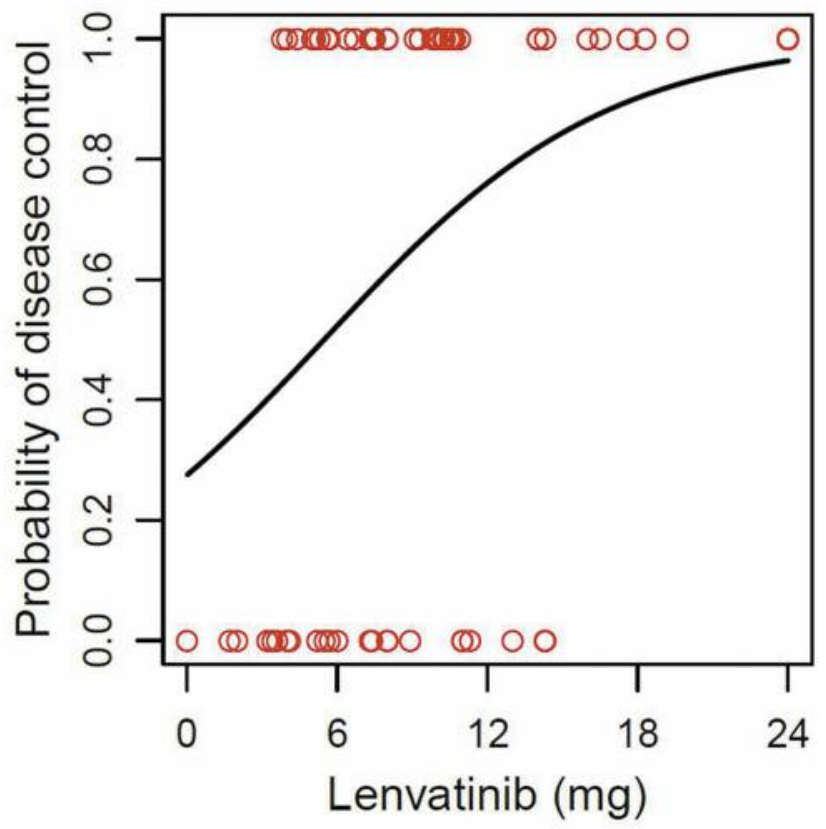

Figure 3. Dose-dependence of the tumor-shrinkage rate. Two different logistic models were analyzed concerning the degree of tumor response: $A$ tumor-shrinkage model (A) and a disease-control model (B). The dependent variable was whether the individual tumor-shrinkage rate (\%/week) at each time point achieved the high-risk shrinkage rate for the tumor-shrinkage model, while for the disease-control model it was $0 \% /$ week and no appearance of new malignant lesions. The explanatory variable was the average daily dose of lenvatinib from the previous computed tomographic examination to the assessment time point.

The present results agreed with previous studies in that tumor decrease was dose-dependent at clinical doses $(17$, 18). Impressively, lenvatinib has been reported to induce early tumor shrinkage defined as $\geq 10 \%$ tumor size decrease within the first 8 weeks (13). From the present results, tumor size decreased rapidly in the relative early phase, followed by a gradual decrease in the relatively late phase. This pattern of tumor-size change induced by lenvatinib was also reported by others (17). In that study, tumor size reduced by $24.7 \%$ during the first 8 weeks (17), which was a rate similar to that of our study. These observations could be at least partly explained by change in dose intensity because it was parallel with change in tumor size. Moreover, a significant relationship between dose and tumor-shrinkage rate was confirmed. The dosage of $11.62 \mathrm{mg}$ was calculated as providing a $50 \%$ probability that the tumor-shrinkage rate would lead to the level of complications. This result indicates that rapid tumor decline would be induced in the short term when lenvatinib is administered at levels over this dosage, such as the approved dose of $24 \mathrm{mg}$. Therefore, dose reduction could be considered for patients with a risk of complications. On the other hand, the dose with a $50 \%$ probability that tumor would not grow was $5.48 \mathrm{mg}$. This indicates that tumor-suppressive effects of lenvatinib could be expected even with a low dose. As seen here, the optimal range of lenvatinib dose to maintain both an anticancer effect and safety could be narrow. Therefore, individual dose adjustment would be necessary.

On the risk factor analysis, ATC, tumor invasion, and leukocytopenia were identified risks associated with developing a fistula or tumor-related bleeding, while they were not related to tumor-shrinkage rate. This suggests that these factors might not influence tumor response to lenvatinib but rather other aspects which increased the risk of complications such as those involving the environment surrounding the tumor. It is physiologically reasonable that the presence of tumor invasion would increase the risk of complications. The thyroid tumor itself might pose a risk due to its anatomical location close to the trachea, esophagus, and major vessels such as carotid arteries. The incidence of life-threatening hemorrhage is considered to be higher in patients with head and neck cancer rather than in the whole cancer population for this reason (19). In addition, ATC is well-known as being unresectable, rapidly progressive, and infiltrating with high frequency $(7,20)$. All cases of ATC had invasion in this study. Thus, the histology of ATC might result in complications due to local growth and invasion, or other factors such as the tumor environment. Regarding leukocytopenia, to our knowledge, 
there are no reports indicating a relationship with fistula or tumor-related bleeding. Further studies are needed to confirm this relationship. Moreover, previous studies using population pharmacokinetic analyses indicated that several covariates affect the level of exposure to lenvatinib, including body weight, use of drugs that interact with cytochrome P450 $3 A 4$ (which is the dominant metabolyzing enzyme of lenvatinib), serum albumin level, serum alkaline phosphatase level, and the presence of cancer $(21,22)$. Thus, in addition to our findings, individual parameters of these factors also need to be evaluated in clinical settings because they could potentially affect tumor response by alteration of drug exposure. Interestingly, several case reports have also suggested that complications might be associated with experience of radiation therapy in patients who received other angiogenesis inhibitors $(12,23-25)$. In the present study, two out of three patients with complications did not receive radiation therapy, indicating that experience of radiation would not be necessary for the development of a fistula or tumor-related bleeding. However, the possibility remains that risk factors were not fully identified due to the small sample size. It could also be a problem that confounding factors including inhibitory factors were not statistically adjusted for. These are limitations of the present study.

In conclusion, lenvatinib-induced fistula formation and tumor-related bleeding were found to appear at 10.4 weeks with a tumor decrease of $19.2 \%$ from the start of therapy. When administration of lenvatinib is planned, individual dose adjustment should be considered in the clinical setting.

\section{Conflicts of Interest}

Seiji Yano obtained a research grant from Eisai Inc. All other Authors have no conflicts of interest in regard to this study.

\section{Authors' Contributions}

Y. Staub, A. Nishiyama, Y. Suga, and S. Yano participated in research design. Y. Staub, A. Nishiyama, and M. Fujita performed data analysis. Y. Staub, A. Nishiyama, Y. Suga, M. Fujita, R. Matsushita, and S. Yano wrote or contributed to the writing of the article.

\section{References}

1 Schlumberger M, Tahara M, Wirth LJ, Robinson B, Brose MS, Elisei R, Habra MA, Newbold K, Shah MH, Hoff AO, Gianoukakis AG, Kiyota N, Taylor MH, Kim SB, Krzyzanowska MK, Dutcus CE, de las Heras B, Zhu J and Sherman SI: Lenvatinib versus placebo in radioiodine-refractory thyroid cancer. N Engl J Med 372(7): 621-630, 2015. PMID: 25671254. DOI: 10.1056/NEJMoa1406470

2 Valerio L, Pieruzzi L, Giani C, Agate L, Bottici V, Lorusso L, Cappagli V, Puleo L, Matrone A, Viola D, Romei C, Ciampi R, Molinaro $\mathrm{E}$ and Elisei R: Targeted therapy in thyroid cancer: State of the art. Clin Oncol 29(5): 316-324, 2017. PMID: 28318881. DOI: $10.1016 /$ j.clon.2017.02.009
3 Brose MS, Nutting CM, Jarzab B, Elisei R, Siena S, Bastholt L, de la Fouchardiere C, Pacini F, Paschke R, Shong YK, Sherman SI, Smit JWA, Chung J, Kappeler C, Peña C, Molnár I and Schlumberger MJ: Sorafenib in radioactive iodine-refractory, locally advanced or metastatic differentiated thyroid cancer: A randomised, double-blind, phase 3 trial. The Lancet 384(9940): 319-328, 2014. PMID: 24768112. DOI: 10.1016/S01406736(14)60421-9

4 Wells SA Jr., Robinson BG, Gagel RF, Dralle H, Fagin JA, Santoro M, Baudin E, Elisei R, Jarzab B, Vasselli JR, Read J, Langmuir P, Ryan AJ and Schlumberger MJ: Vandetanib in patients with locally advanced or metastatic medullary thyroid cancer: A randomized, double-blind phase III trial. J Clin Oncol 30(2): 134-141, 2012. PMID: 22025146. DOI: 10.1200/JCO. 2011.35.5040

5 Tohyama O, Matsui J, Kodama K, Hata-Sugi N, Kimura T, Okamoto K, Minoshima Y, Iwata M and Funahashi Y: Antitumor activity of lenvatinib (e7080): An angiogenesis inhibitor that targets multiple receptor tyrosine kinases in preclinical human thyroid cancer models. J Thyroid Res 2014: 638747, 2014. PMID: 25295214. DOI: 10.1155/2014/638747

6 Takahashi S, Kiyota N, Yamazaki T, Chayahara N, Nakano K, Inagaki L, Toda K, Enokida T, Minami H, Imamura Y, Fukuda N, Sasaki T, Suzuki T, Ikezawa H, Dutcus CE and Tahara M: A phase II study of the safety and efficacy of lenvatinib in patients with advanced thyroid cancer. Future Oncol 15(7): 717-726, 2019. PMID: 30638399. DOI: 10.2217/fon-20180557

7 Tahara M, Kiyota N, Yamazaki T, Chayahara N, Nakano K, Inagaki L, Toda K, Enokida T, Minami H, Imamura Y, Sasaki T, Suzuki T, Fujino K, Dutcus CE and Takahashi S: Lenvatinib for anaplastic thyroid cancer. Front Oncol 7: 25, 2017. PMID: 28299283. DOI: $10.3389 /$ fonc. 2017.00025

8 Schlumberger M, Jarzab B, Cabanillas ME, Robinson B, Pacini F, Ball DW, McCaffrey J, Newbold K, Allison R, Martins RG, Licitra LF, Shah MH, Bodenner D, Elisei R, Burmeister L, Funahashi Y, Ren M, O'Brien JP and Sherman SI: A phase II trial of the multitargeted tyrosine kinase inhibitor lenvatinib (e7080) in advanced medullary thyroid cancer. Clin Cancer Res 22(1): 44-53, 2016. PMID: 26311725. DOI: 10.1158/10780432.CCR-15-1127

9 Haddad RI, Schlumberger M, Wirth LJ, Sherman EJ, Shah MH, Robinson B, Dutcus CE, Teng A, Gianoukakis AG and Sherman SI: Incidence and timing of common adverse events in lenvatinib-treated patients from the select trial and their association with survival outcomes. Endocrine 56(1): 121-128, 2017. PMID: 28155175. DOI: 10.1007/s12020-017-1233-5

10 Cabanillas ME, Schlumberger M, Jarzab B, Martins RG, Pacini F, Robinson B, McCaffrey JC, Shah MH, Bodenner DL, Topliss D, Andresen C, O'Brien JP, Ren M, Funahashi Y, Allison R, Elisei R, Newbold K, Licitra LF, Sherman SI and Ball DW: A phase 2 trial of lenvatinib (e7080) in advanced, progressive, radioiodine-refractory, differentiated thyroid cancer: A clinical outcomes and biomarker assessment. Cancer 121(16): 2749-2756, 2015. PMID: 25913680. DOI: $10.1002 / \mathrm{cncr} .29395$

11 Ye X, Zhu Y and Cai J: Relationship between toxicities and clinical benefits of newly approved tyrosine kinase inhibitors in thyroid cancer: A meta-analysis of literature. J Cancer Res Ther 11 (Suppl 2): C185-190, 2015. PMID: 26506873. DOI: 10.4103/ 0973-1482.168182 
12 Blevins DP, Dadu R, Hu M, Baik C, Balachandran D, Ross W, Gunn B and Cabanillas ME: Aerodigestive fistula formation as a rare side-effect of antiangiogenic tyrosine kinase inhibitor therapy for thyroid cancer. Thyroid 24(5): 918-922, 2014. PMID: 24635127. DOI: $10.1089 /$ thy.2012.0598

13 Masaki C, Sugino K, Saito N, Saito Y, Tanaka T, Ogimi Y, Maeda T, Osaku T, Akaishi J, Hames KY, Tomoda C, Suzuki A, Matsuzu K, Uruno T, Ohkuwa K, Kitagawa W, Nagahama M, Takami $\mathrm{H}$ and Ito K: Lenvatinib induces early tumor shrinkage in patients with advanced thyroid carcinoma. Endocr J 64(8): 819-826, 2017. PMID: 28659544. DOI: 10.1507/endocrj.EJ170104

14 Costa R, Carneiro BA, Chandra S, Pai SG, Chae YK, Kaplan JB, Garrett HB, Agulnik M, Kopp PA and Giles FJ: Spotlight on lenvatinib in the treatment of thyroid cancer: Patient selection and perspectives. Drug Des Devel Ther 10: 873-884, 2016. PMID: 27013865. DOI: 10.2147/DDDT.S93459

15 National Cancer Institute. Protocol development: Cancer Therapy Evaluation Program, 2017. Available from: https:// ctep.cancer.gov/protocolDevelopment/electronic_applications/ctc .htm\#ctc_50

16 Eisenhauer EA, Therasse P, Bogaerts J, Schwartz LH, Sargent D, Ford R, Dancey J, Arbuck S, Gwyther S, Mooney M, Rubinstein L, Shankar L, Dodd L, Kaplan R, Lacombe D and Verweij J: New response evaluation criteria in solid tumours: Revised RECIST guideline (version 1.1). Eur J Cancer 45(2): 228-247, 2009. PMID: 19097774. DOI: 10.1016/j.ejca. 2008.10.026

17 Robinson B, Schlumberger M, Wirth LJ, Dutcus CE, Song J, Taylor MH, Kim SB, Krzyzanowska MK, Capdevila J, Sherman SI and Tahara M: Characterization of tumor size changes over time from the phase 3 study of lenvatinib in thyroid cancer. $\mathrm{J}$ Clin Endocrinol Metab 101(11): 4103-4109, 2016. PMID: 27548104. DOI: $10.1210 /$ jc.2015-3989

18 Hayato S, Shumaker R, Ferry J, Binder T, Dutcus CE and Hussein Z: Exposure-response analysis and simulation of lenvatinib safety and efficacy in patients with radioiodinerefractory differentiated thyroid cancer. Cancer Chemother Pharmacol 82(6): 971-978, 2018. PMID: 30244318. DOI: $10.1007 / \mathrm{s} 00280-018-3687-4$
19 Harris DG and Noble SI: Management of terminal hemorrhage in patients with advanced cancer: A systematic literature review. J Pain Symptom Manage 38(6): 913-927, 2009. PMID: 19833478. DOI: 10.1016/j.jpainsymman.2009.04.027

20 Sugitani I, Onoda N, Ito KI and Suzuki S: Management of anaplastic thyroid carcinoma: The fruits from the ATC Research Consortium of Japan. J Nippon Med Sch 85(1): 18-27, 2018. PMID: 29540641. DOI: 10.1272/jnms.2018_85-3

21 Gupta A, Jarzab B, Capdevila J, Shumaker R and Hussein Z: Population pharmacokinetic analysis of lenvatinib in healthy subjects and patients with cancer. Br J Clin Pharmacol 81(6): 1124-1133, 2016. PMID: 26879594. DOI: 10.1111/bcp.12907

22 Tamai T, Hayato S, Hojo S, Suzuki T, Okusaka T, Ikeda K and Kumada H: Dose finding of lenvatinib in subjects with advanced hepatocellular carcinoma based on population pharmacokinetic and exposure-response analyses. J Clin Pharmacol 57(9): 11381147, 2017. PMID: 28561918. DOI: 10.1002/jcph.917

23 Seiwert TY, Haraf DJ, Cohen EE, Stenson K, Witt ME, Dekker A, Kocherginsky M, Weichselbaum RR, Chen HX and Vokes EE: Phase I study of bevacizumab added to fluorouracil- and hydroxyurea-based concomitant chemoradiotherapy for poorprognosis head and neck cancer. J Clin Oncol 26(10): 17321741, 2008. PMID: 18375903. DOI: 10.1200/JCO.2007.13.1706

24 Spigel DR, Hainsworth JD, Yardley DA, Raefsky E, Patton J, Peacock N, Farley C, Burris HA, 3rd and Greco FA: Tracheoesophageal fistula formation in patients with lung cancer treated with chemoradiation and bevacizumab. J Clin Oncol 28(1): 43-48, 2010. PMID: 19901100. DOI: 10.1200/ JCO. 2009.24.7353

25 Basille D, Andrejak M, Bentayeb H, Kanaan M, Fournier C, Lecuyer E, Boutemy M, Garidi R, Douadi Y and Dayen C: Bronchial fistula associated with sunitinib in a patient previously treated with radiation therapy. Ann Pharmacother 44(2): 383386, 2010. PMID: 20118139. DOI: 10.1345/aph.1M469

Received May 10, 2019

Revised June 3, 2019

Accepted June 7, 2019 